\title{
A new endoscopic fixation method using the commercially available Multi-Clamp: the "clamp technique"
}

When endoscopic submucosal dissection (ESD) is performed in an unstable setting, removing one's right hand from the endoscope to manipulate the ESD knife can make it difficult to maintain visibility during the surgery. Various tools and methods have been developed to overcome this challenge [1-3]; however, in many cases, the assistant is asked to fix the endoscope owing to issues such as difficulty in performing the complicated technique and limitations of the ESD knife available for use. We report our newly devised endoscopic fixation method using the commercially available Multi-Clamp (Taiyo Electric Ind. Co., Ltd., Tokyo, Japan).
Before insertion of the endoscope, a Multi-Clamp was clamped with gauze into the base (near the opening of the forceps) of the soft part of the endoscope, which was then inserted. Once the lesions were reached, the Multi-Clamp and gauze were shifted to an appropriate position on the soft part of the endoscope and
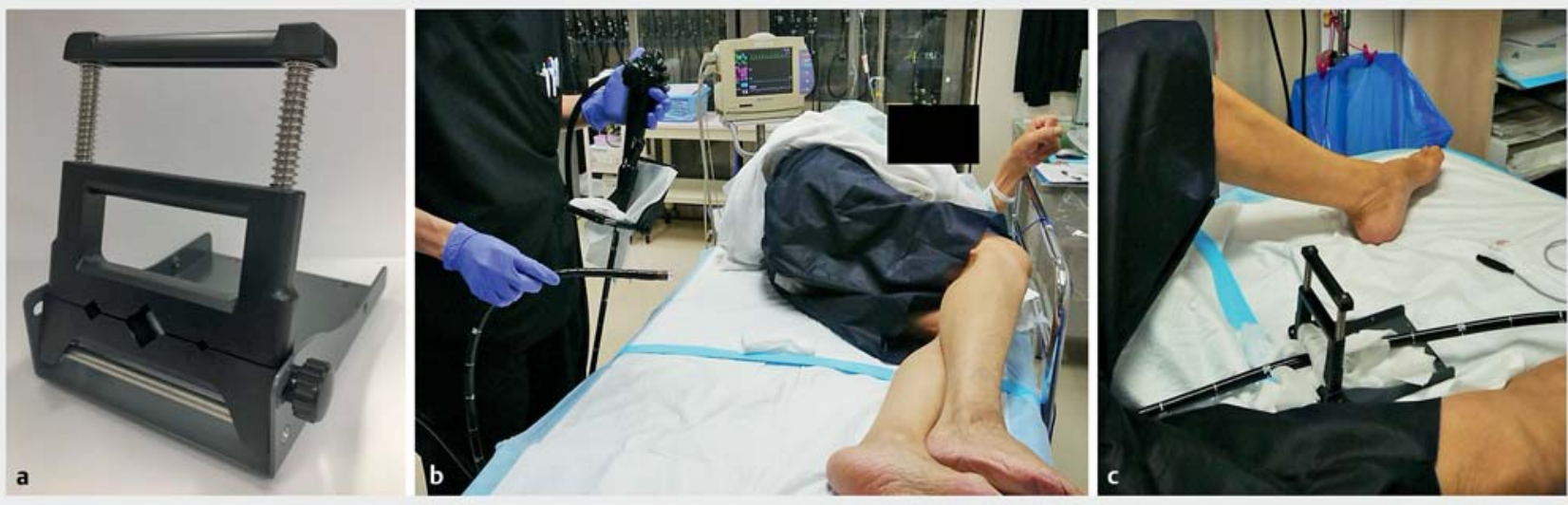

- Fig. 1 How to use the Multi-Clamp. a The Multi-Clamp. b Before insertion of the endoscope, a Multi-Clamp was clamped with gauze into the base (near the opening of the forceps) of the soft part of the endoscope, which was then inserted. c Once the lesions were reached, the Multi-Clamp and gauze were shifted to an appropriate position on the soft part of the endoscope and clamped again before the procedure was initiated.
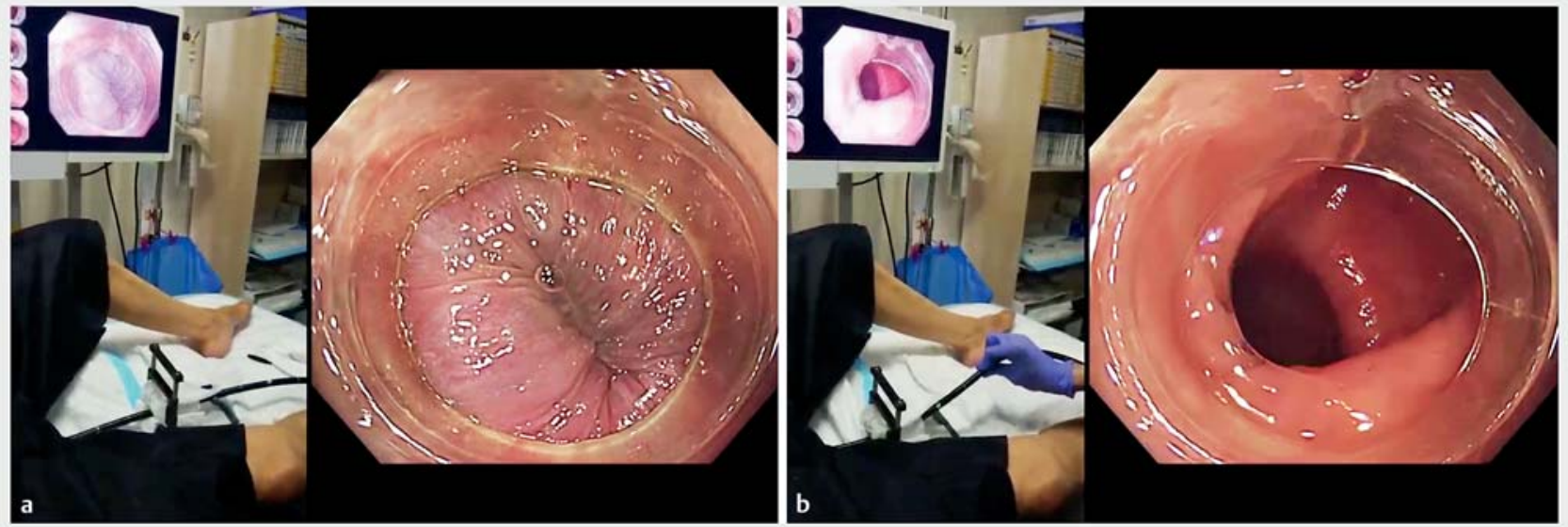

- Fig. 2 Demonstration of the endoscopic fixation method using a commercially available Multi-Clamp: the "clamp technique." a In an unstable setting (the location of this image is the anal canal), even if the ESD knife is manipulated by removing one's right hand from the endoscope, the weight of the main body of the Multi-Clamp allows the endoscope to be fixed in place, allowing visibility to be maintained during the surgery. b The right amount of clamping pressure from the mechanical spring force and the presence of the gauze in between allows twisting manipulation with the right hand. 


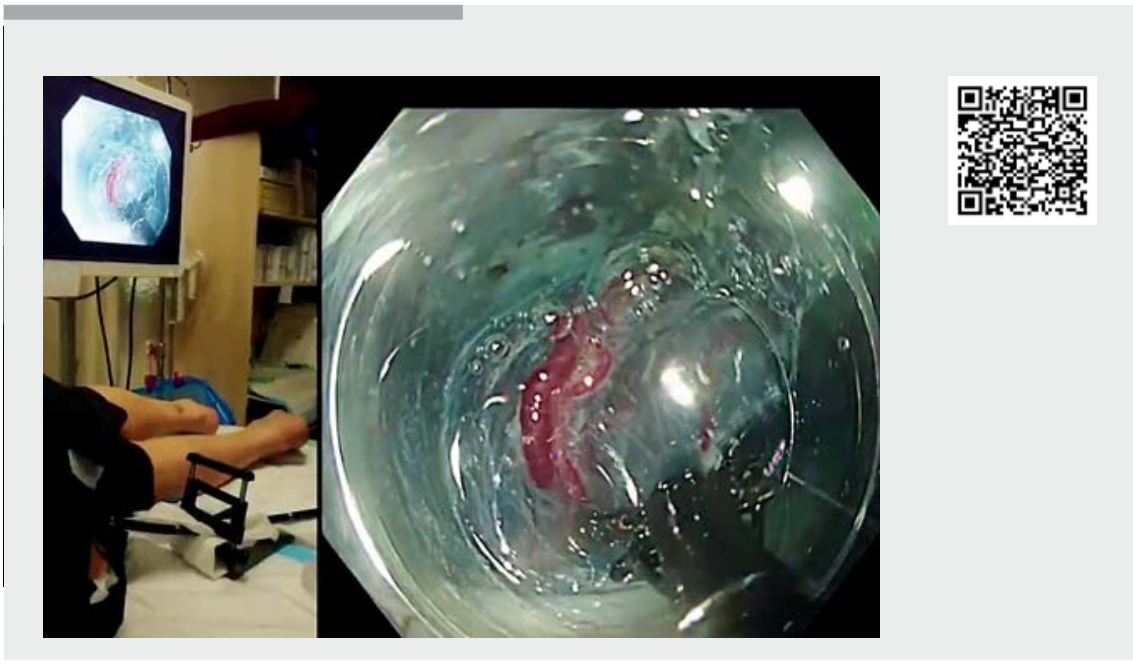

Video 1 A new endoscopic fixation method using a commercially available MultiClamp: the "clamp technique."

clamped again before the procedure was initiated ( $\bullet$ Fig. 1 ). In an unstable setting, even if the ESD knife is manipulated by removing one's right hand from the endoscope, the weight of the main body of the Multi-Clamp allows the endoscope to be fixed in place, allowing visibility to be maintained during the surgery. The right amount of clamping pressure from the mechanical spring force and the presence of the gauze in between allows twisting manipulation with the right hand. This also allows for forward and backward movement of the endoscope ( $\boldsymbol{F}$ Fig. 2; - Video 1).

The Smart Shooter is a useful tool that allows control of the ESD knife while the right hand is fixed in place [3]. However, there are constraints on the available ESD knives that can be used, and these cannot be used in colonoscopies. It is possible to use our method with all endoscopic devices and for all types of endoscopes.

Endoscopy_UCTN_Code_TTT_1AQ_2AJ
Corresponding author

Satoshi Abiko, MD, PhD

Department of Gastroenterology and Hepatology, Hakodate Municipal Hospital, 10-Ban 1-Gou 1-Chome Minato-chou, Hakodate 041-8680, Japan

Fax: +81-138-434434

abiko1982@gmail.com

\section{References}

[1] Nishizawa T, Uraoka T, Suzuki H et al. Control of the treatment device for endoscopy by the left hand: two-fingers method. Gastrointest Endosc 2014; 80: 1206-1207

[2] Yoshimoto T, Takihara H, Yoshihara T et al. Usefulness of "Nelaton Attachment" for endoscopic submucosal dissection of colorectal neoplasms. Endosc Int Open 2019; 7 : E1187-E1191

[3] Kikuchi D, lizuka T, Yamada A et al. Feasibility of a newly developed thumb control device for simultaneous manipulation of the endoscope and treatment devices in endoscopic submucosal dissection: a clinical feasibility study. Digestion 2016; 94: 123-128

Kohya, and Dr. Kazuharu Suzuki in the Department of Gastroenterology and Hepatology, Hakodate Municipal Hospital, for their kind support and advice. We are very grateful for the wonderful staff in the endoscopic room and ward of Hakodate Municipal Hospital.

\section{Competing interests}

The authors declare that they have no conflict of interest.

The authors

Satoshi Abiko, Shuichi Miyamoto, Ryo Sugiura, Kenji Kinoshita, Kazuteru Hatanaka, Yoshiya Yamamoto, Hirohito Naruse Department of Gastroenterology and Hepatology, Hakodate Municipal Hospital, Hakodate, Japan
Endoscopy 2021; 53: E301-E302

DOI 10.1055/a-1270-6443

ISSN 0013-726X

published online 8.10 .2020

(C) 2020. Thieme. All rights reserved.

Georg Thieme Verlag KG, Rüdigerstraße 14, 70469 Stuttgart, Germany

\section{ENDOSCOPY E-VIDEOS}

https://eref.thieme.de/e-videos

口发直 Endoscopy E-Videos is a free access online section, reporting 口if: on interesting cases and new techniques in gastroenterological endoscopy. All papers include a high quality video and all contributions are freely accessible online.

This section has its own submission website at https://mc.manuscriptcentral.com/e-videos 